\title{
Isolation of Bacteria Contaminants from Tetra Packed Yoghurt
}

\author{
Orji Jerry O. ${ }^{1}$, Agah Maduka V ${ }^{1}$., Ekuma Uchechukwu $\mathrm{O}^{1}$., Ogbu Kenneth I. ${ }^{2}$, \\ Olaosebikan O.O. ${ }^{3}$, Onu Euslar N. ${ }^{4}$, Elsie Chidimma E. ${ }^{1}$ and Okeh Boniface ${ }^{1}$ \\ ${ }^{I}$ Department of Applied Microbiology, Ebonyi State University, Abakaliki, Nigeria. \\ ${ }^{2}$ Department of Biological Sciences, Ebonyi State University, Abakaliki, Nigeria. \\ ${ }^{3}$ Department of Biology, Microbiology and Biotechnology Faculty of Science, Federal University Ndufu-Alike \\ Ikwo, Nigeria. \\ ${ }^{4}$ Ebonyi State School of Health Mgbo, Ohaukwu Local Government Area, Ebonyi State, Nigeria.
}

\begin{abstract}
This work was designed to isolate the microorganisms associated with the spoilage of yogurt products using standard microbiological and biochemical procedure. Six different brands of tetra packed yoghurt which had over stayed and the shelf-life deteriorated were purchased from the production company, market stores that were unable to sell out their yoghurt prior to the expiry date, and from hawkers in Abakaliki metropolis. Two samples of each brand were used and the brand were designated $A, B, C, D, E, F$, giving a total of 12 yoghurt samples. Bergey's manual was used for bacteria identification. The results reveales the presence of Klebsiella pneumonia, Citrobacter sp, Pseudomonas sp. Escherichia coli. Proteus sp and Vibrio sp. in the samples. The isolation of Citrobacter sp, klebsiella pneumonia, Escherichia coli. Pseudomonas sp, Proteus $s p$ and Vibrio $s p$ is a clear indication of a deplorable state of poor hygienic and sanitary practices employed in the processing and packaging of the yoghurt product.
\end{abstract}

Keywords: Yoghurt spoilage, Tetra packed yoghurt and Bacteria species.

\section{Introduction}

Yoghurt is a diary product produced by bacteria controlled fermentation of milk. The bacteria used to produce yoghurt are known as yoghurt cultures. Fermentation of lactose by these bacteria produces lactic acid, which acts on milk protein to give yoghurt its texture and characteristic tang. Worldwide, cow's milk protein of mainly comprises casein, is most commonly used to make yoghurt, but milk from water buffalo, goats, sheep, camels and yaks are also used in various parts of the world [1].

However, evaporated pasteurized powdered milk containing about $40 \%$ milk solid like the skim or whole milk can also be used. The acid in the yoghurt restricts the growth of food poisoning bacteria and some spoilage bacteria. In theory, the milk of any mammal could be used to produce yoghurt. Dairy yoghurt is produced using a culture of Lactobacillus delbrueckii sub spp. bulgaricus and Streptococcus salivarius subsp. thermophilus. In addition, Lactobacillus acidophilus and Lactobacillus casei are also sometimes added during or after culturing yogurt [2]. The world is derived from Turkish: Yogurt and is related to the obsolete verb yogmak " to be curdled or coagulated; to thicken". The milk is first heated to about $80^{\circ} \mathrm{C}$ to kill any undesirable bacteria and to denature the milk proteins so they set together rather than form curds. The milk is then cooled to about $45^{\circ} \mathrm{C}$. The bacteria culture is added and the temperature is maintained for 4 to 7 hours to allow fermentation to take place. Commercial yogurt production is composed of the following steps: Pretreatment of milk (standardization, fortification, and lactose hydrolysis), homogenization, heat treatment, cooling at incubation temperature, inoculation with starter culture, fermentation, cooling post fermentation treatment (flavouring, fruit addition, pasteurization) refrigeration and packaging. For set yogurt, the packaging into individual containers is carried out before fermentation. In addition to the above steps, the starter culture is propagated in parallel although a batch process is followed. The commercial production of yogurt is carried out in an automated continuous fertmentation process. A good strain of starter culture not only affects the flavor and aroma, it can also speed up the process and thus reduces the effective equipment lost [3].

\section{Aim and Objective}

The aim of this project work was to isolate and characterized the bacteria associated with the spoilage of tetra packed yogurt product sold in the Abakpa main market Abakaliki and some streets around the market.

\section{Materials And Methods}

\section{Sample Collection}

Six different brands of tetra packed yoghurts which had over stayed and the shelf-life deteriorated were purchased from the market stores that were unable to sell out their yoghurts prior to the expiry date, and from hawkers in Abakaliki metropolis. Two samples of each brand were used and the brands were designated A, B, 
C, D, E, F, giving a total of 12 yoghurt samples. The samples were brought to the laboratory and were analyzed after collection.

\section{Analysis of Sample}

Each sample was serially diluted using sterile distilled water as diluents [4]. $9 \mathrm{ml}$ of distilled water was measured out into test tubes using separate sterile pipettes; lml of yoghurt sample was measured out into the first test tube properly mixed.

Using a different pipette, $1 \mathrm{ml}$ from the first test tube was pipette into the second test tube already containing $9 \mathrm{ml}$ of distilled water. This continued following the same procedure till the last dilution (i.e. the last test tube). Using the spread plate method $1 \mathrm{ml}$ of $10^{-5}$ dilution of each sample unit from the test tube was pipette into sterile Petri dishes with their duplicates on the center of nutrient agar plates and spread evenly over the surface with a sterile bent rod. This was incubated at $37^{\circ} \mathrm{C}$ for $24 \mathrm{hrs}$.

\section{Purification of Isolates}

After incubation, colonies developing on plates were randomly picked and subcultured on fresh nutrient agar to obtain pure culture of the isolate. Using wire loop, it was inoculated on Petri dishes containing MacConkey agar for coliform/entrobactericeae counts at $37^{\circ} \mathrm{C}$ for 24 hours, and $37^{\circ} \mathrm{C}$ for Salmonella Shigella agar plate.

\section{Identification of Isolates}

Identification of isolates was based on cultural features (such as notility, Gram-reaction, cell arrangement and shape) and biochemical features. The results obtained were then compared with standard references for proper identification of the isolates; Bergey's manual was used for bacteria identification [5].

\section{Morphological Characteristics Gram Staining}

The method used was that described by Thomas and Carpenter, (1973), [6]. Smear of the isolates were prepared and heat fixed on clean grease free slides. The smear stained for Imin with crystal violet. This was washed out with a gentle running tap water and the slides were flooded with dilute Gram iodine solution. This was washed off with water and the smear was decolourized with $75 \%$ alcohol till the blue colour no more dripped out (about 30seconds). The smear was then counter stained with safranine solution for about 10seconds. Finally, the slides were washed with tap water and air dried. The slide was observed under the microscope using oil immersion x 100 objective lens. The Gram positive organisms appeared purple while Gram negative organism appeared red.

\section{Results}

The results are presented in Tables 1 and 2. The morphological and biochemical characteristics of bacteria isolated from the yoghurt samples are shown in table 1. The distribution or rate of occurence of bacteria isolated from different brands of yoghurt is displayed in (table 2). The bacteria isolated include: Klebsiella pneumonia, Citrobacter sp, Pseudomonas sp. Escherichia coli. Proteus sp and Vibrio sp.

Table 1: Biochemical and Morphological Characteristics of Isolated Bacteria

\begin{tabular}{|c|c|c|c|c|c|c|c|c|}
\hline & $\begin{array}{l}\text { Morphological/cultural } \\
\text { characteristics }\end{array}$ & & $\begin{array}{l}\text { Biochemical } \\
\text { features }\end{array}$ & & & & & Probable organism \\
\hline $\begin{array}{l}\text { Sample } \\
\text { code }\end{array}$ & Gram reaction & Motility & Oxidase & Inodle & MR & $\mathrm{VP}$ & citrate & \\
\hline 1 & -RODS & + & - & + & + & - & + & Citrobacter $s p$ \\
\hline 2 & -RODS & - & - & - & - & - & - & Klebsiella pneumonia \\
\hline 3 & -RODS & + & - & + & - & - & - & Escherichia coli \\
\hline 4 & -RODS & + & - & + & - & - & - & Escherichia coli \\
\hline 5 & -RODS & + & + & + & - & - & - & Pseudomonas sp \\
\hline 6 & -RODS & + & + & + & - & - & + & Pseudomonas sp \\
\hline 7 & -RODS & + & - & + & + & - & + & Proteus sp \\
\hline 8 & -RODS & + & - & + & - & - & - & Escherichia coli \\
\hline 9 & -RODS & + & - & + & - & - & - & Escherichia coli \\
\hline 10 & -RODS & + & - & - & + & - & + & Vbrio sp \\
\hline 11 & -RODS & + & - & + & + & - & + & Citrobacter $s p$ \\
\hline 12 & -RODS & + & + & + & - & - & + & Pseudomonas sp \\
\hline
\end{tabular}


Table 2: Distribution of Isolated Bacteria From Yoghurt Samples

\begin{tabular}{|l|l|l|l|l|l|l|l|}
\hline Sample code & Citrobacter sp & Kilebsiella pneumonia & Escherichia Coli & \multicolumn{2}{|l|}{ Pseudomonas sp } & Proteus sp & \multicolumn{1}{l|}{ Vibrio sp } \\
\hline A & + & + & + & - & + & - \\
\hline B & - & - & + & + & - & - \\
\hline C & - & - & + & + & - & + & - \\
\hline D & + & - & + & - & + & + \\
\hline E & - & + & + & + & + & + \\
\hline F & + & - & + & - & - \\
\hline
\end{tabular}

Keys:

+ indicate positive

- indicate negative

$\mathrm{A}=$ SAN Sweetened yogurt

$\mathrm{B}=$ Fresho yogurt

$\mathrm{C}=$ Pasture yogurt

$\mathrm{D}=$ Jossy yogurt

$\mathrm{E}=$ Rapha yogurt

$\mathrm{F}=$ Greenfield yogurt

\section{Discussion}

In this study, the isolation Citrobacter sp, klebsiella pneumonia, Escherichia coli. Pseudomonas sp, Proteus $s p$ and Vibrio $s p$ is a clear indication of a deplorable state of poor hygienic and sanitary practices employed in the processing and packaging of the product [7]. The negative aspects of microbial growth include food deterioration and spoilage by decay and food poisoning mainly caused by different bacteria. As growth occurs, microorganisms release their own enzymes into the liquid surrounding them and make food unfit for consumption. Most psychrotrophs are destroyed by pasteurization temperatures, however, some like Pseudomonas $s p$, Proteus sp can produce proteolytic and lipolytic extra cellular enzyme which are heat stable and capable of causing spoilage [8]. From this study the result shows that many yogurt samples were contaminated by microorganisms that have public health implication and those that can cause spoilage. Yogurt has a long history and its benefits have been valued by many people. Improving the health potential of yogurt has become a popular field, and for industrial reason, enhancing the taste and texture as well, storage life of yogurt is an appealing advancement for consumers. Since a vast array of pathogenic microorganisms which are responsible for causing food borne illnesses such as gastroinstestinal disorder, vomiting, diarrhea have been isolated from different brand of yogurts.

Effort should be made by the manufacturers to ensure proper hygiene in their work place. This research work has also identified the major sources of contamination of this yogurt which include: unhygienic practice, poor personal hygiene, bad packaging, and inappropriate pasteurization, contamination of the equipments, contaminated raw materials, unhygienic water and the use of contaminated started culture.

\section{References}

[1] Zemel, M. B., Milstead, A., Gebhardt, L. and Silva, E. (2005). Diary augmentation of total and central fat loss in obese subjects. International Journal of Obesity, 29(4): 391-397.

[2] Wilton, J.M (2004). Yoghurt: A Top Health Food. Blackwell Scientific Publication, Washington. PP. 36-44.

[3] Peter and Pam (2004). The Cambridge Guide to English Usage. Cambridge University Press, USA. PP. 587-588.

[4] Oyeleke, S.B. (2009). Microbial assessment of some commercially prepared yoghurts retailed in Minna. Africa Journal of Microbiology Research. 3(5):245-248.

[5] Okpalugo, J., Ibrahim, K., Izebe, K.S. and Inyang, U.S (2008) Aspect of microbial quality of some milk products in Abuja, Nigeria . Tropical Journal of Phaarmaceutical Research. 7 (4): 1169-1177.

[6] Thomas, C.G. and Carpenter, C.J. (1973). Medical microbiology. $3^{\text {rd }}$ edition. Baucere Tindal, London. PP. 8-9. 